Sinnema, H., Franx, G., Spijker, J., Ruiter, M., Haastrecht, H. van, Verhaak, P., Nuyen, J. Delivering stepped care for depression in general practice: results of a survey amongst general practitioners in the Netherlands. European Journal of General Practice: 2013, 19(4), 221-229

nivel

\begin{tabular}{|l|l|}
\hline $\begin{array}{l}\text { Postprint } \\
\text { Version }\end{array}$ & 1.0 \\
\hline Journal website & http://informahealthcare.com/doi/abs/10.3109/13814788.2013.780018 \\
\hline Pubmed link & http://www.ncbi.nlm.nih.gov/pubmed/?term=23577662 \\
\hline DOI & $10.3109 / 13814788.2013 .780018$ \\
\hline
\end{tabular}

This is a NIVEL certified Post Print, more info at http://www.nivel.eu

\title{
Delivering stepped care for depression in general practice: Results of a survey amongst general practitioners in the Netherlands
}

\author{
HENNY SINNEMA ${ }^{1}$, GERDIEN FRANX ${ }^{1}$, JAN SPIJKER ${ }^{1,2,3}$, MARIJKE RUITER ${ }^{1}$, HARRY VAN \\ HAASTRECHT $^{1}$, PETER VERHAAK ${ }^{4,5}$ \& JASPER NUYEN ${ }^{1}$ \\ ${ }^{1}$ Trimbos Institute, Netherlands Institute of Mental Health and Addiction, The Netherlands, \\ ${ }^{2}$ Pro Persona, Center for Mental Health Care, Arnhem, the Netherlands, \\ ${ }^{3}$ Faculty of Social Sciences, Radboud University Nijmegen Medical Centre, Nijmegen, the \\ Netherlands, \\ ${ }^{4}$ NIVEL Netherlands Institute for Health Services Research, Utrecht, the Netherlands, and \\ ${ }^{5}$ Dept of General Practice, University Medical Centre Groningen, Groningen, the \\ Netherlands
}

Background: Revised guidelines for depression recommend a stepped care approach. Little is known about the implementation of the stepped care model by general practitioners (GPs) in daily practice.

Objectives: To evaluate the performance of Dutch GPs in their general practice regarding important elements of the stepped care model (identification, severity assessment and stepped care treatment allocation) shortly before the revised Dutch multidisciplinary guideline for Depressive Disorders was published.

Methods: Data was collected through a self-report questionnaire sent to 500 randomly selected GPs. Multivariate logistic regression analyses were employed to investigate whether GP-related characteristics were associated with GPs ' self-reported performance.

Results: The study involved 194 GPs (response rate: 39\%). Responses indicated that $37 \%$ paid systematic attention to depression identification, 33\% used a screening instrument, and $63 \%$ determined the severity of newly diagnosed depression, generally without using an instrument. Most GPs (72\%) indicated to allocate stepped care treatment to the majority of their patients newly diagnosed with depression. However, more than $40 \%$ indicated to start with antidepressants, either alone or in combination with psychotherapy.

Assessing the severity of newly diagnosed depression and clinical experience were positively associated with allocating stepped care treatment. Structural collaboration with mental health professionals was positively associated with assessing severity. 
Sinnema, H., Franx, G., Spijker, J., Ruiter, M., Haastrecht, H. van, Verhaak, P., Nuyen, J. Delivering stepped care for depression in general practice: results of a survey amongst general practitioners in the Netherlands. European Journal of General Practice: 2013, 19(4), 221-222

Conclusion: Delivering stepped care for depression in daily general practice could be further improved. Collaboration with mentalhealth professionals and routine severity assessment of diagnosed depression are positively associated with allocating stepped care.

\section{INTRODUCTION}

Depression is a common mental disorder that has a negative impact on everyday functioning, causes great suffering, and incurs both high care costs and costs associated with production losses $(1-3)$. Most adults who seek help for their depression are treated in general practice (4). From 2008 up to 2010 the Dutch College of General Practitioners (NHG) collaborated with allied health professionals, patient organizations and specialty care colleges, to revise the overarching multidisciplinary guideline for Depressive Disorders (5). The revised multidisciplinary guideline was published in 2010 and differed from previous guidelines by explicitly recommending a stepped care model for the delivery of evidence based interventions for depression (6). The NHG authorised the primary care part. The recently revised NHG guideline on depression corresponds largely with the multidisciplinary guideline (7). These stepped care recommendations are in line with recommendations from published guidelines in other countries $(8-10)$. The stepped care model offers a range of several effective treatments. Depending on the severity of the depression, a treatment is allocated, starting with the least intensive treatment that is still expected to generate effects. Patients with subthreshold and mild depression are offered interventions of low intensity. More intensive treatment options are appropriate for patients who do not successfully respond to low-intensity interventions, or for patients whose symptoms are more severe. To allocate stepped care adequately, patients have to be identified timely, and the severity of depressive symptoms has to be assessed and monitored. Instruments can be helpful for the recognition of depression and the determination of severity (6,7). Although, main principles underlying stepped care models are rather similar in different European countries, there is variation in the specific focus and content of various stepped care models $(11-13)$.

Little is known about the implementation of the stepped care model by general practitioners (GPs) in daily practice. However, previous research suggests that GPs ' actual performance might not fully comply with the stepped care model. Underrecognition and consequently under-treatment of depression have been reported, whereas more severe depression is more likely to be recognized (14). When treatment is initiated, one quarter to half of the patients do not receive optimal treatment for a depression in general practice (15).

The aims of this study were to describe the performance of Dutch GPs in daily practice regarding depression identification and screening, severity assessment of newly diagnosed depression and stepped care allocation; in addition, to identify factors influencing the provision of these elements of depression care. 
Sinnema, H., Franx, G., Spijker, J., Ruiter, M., Haastrecht, H. van, Verhaak, P., Nuyen, J. Delivering stepped care for depression in general practice: results of a survey amongst general practitioners in the Netherlands. European Journal of General Practice: 2013, 19(4), 221-229

\section{METHODS}

\section{Design and variables measured}

A survey was conducted among GPs at the end of 2009,using a self-administered questionnaire, developed by our research team and professionals in psychiatry and primary mental healthcare.

GPs were asked questions about the actual performance in their general practice concerning: (1) depression identification and screening; (2) assessment of severity of newly diagnosed depression; and (3) delivering stepped care to patients with a newly diagnosed depression.

Apart from being asked about allocating stepped care in general, GPs were asked how often specific interventions recommended by the multidisciplinary guideline were used in their practice, ranging from low-intensity (watchful waiting) to highintensity (combination of antidepressant treatment and psychotherapy)interventions (6). These questions had two (yes/no) or four ( ' rarely/less than $50 \% /$ more than $50 \% /($ almost) always' ) response categories. GPs who indicated not to use a screening instrument, not to assess depression severity or not to use an instrument for assessing severity, respectively, were asked to point out the three most important reasons for not doing so (e.g. perceived patient characteristics, lack of time, unfamiliarity with instruments, insufficient knowledge and skills). Additionally, all GPs were asked to indicate the three most important reasons why they sometimes would not treat a patient according to a stepped care approach. All questions about reasons had also an open response category, giving a GP the possibility to report other reasons. These reasons were assessed by two independent raters and subsumed under the closed response categories.

Moreover, questions about GP-related characteristics were part of the survey, to investigate whether they were associated with the self-reported performance of GPs. These characteristics were selected based on literature and included gender, age, clinical experience, having special interest in patients with depression, having followed training in depression care, having participated in any improvement project for depression care (i.e. breakthrough series, a collaborative model for achieving improvement; pharmaceutical therapeutic audit meetings to improve GPs ' prescription behaviour, or other projects) and having structural collaboration with mental health professionals in primary and/or specialized mental health care $(16,17)$. In the Netherlands, structural collaboration between mental health professionals (i.e. nurse, psychologist, psychiatrist) and GPs can be organized in different ways. Either a mental health professional is part-time employed by the GP, ora private primary care mental health professional collaborates with the GP, or consultation by a mental health professional from specialized mental health care is given in general practice.

\section{Participants}

A sample of 500 GPs was randomly selected from the total population of approximately 8500 Dutch GPs(except for GPs who were not willing to participate and GPs who have been selected frequently during the past several years) by NIVEL, the Netherlands Institute for Health Services Research. Recruitment took place by sending information about the study, including the paper questionnaire and a link and login code to the internet, in case a GP preferred to complete the questionnaire online. After three weeks, one reminder was sent to those GPs who did not respond initially. 
Sinnema, H., Franx, G., Spijker, J., Ruiter, M., Haastrecht, H. van, Verhaak, P., Nuyen, J. Delivering stepped care for depression in general practice: results of a survey amongst general practitioners in the Netherlands. European Journal of General Practice: 2013, 19(4), 221-229

\section{Statistical analysis}

Descriptive statistics were used to describe GPs ’ performance regarding depression identification and screening, severity assessment and stepped care treatment as well as the most frequent reasons for not using a screening instrument, not assessing depression severity, not using an instrument for assessing severity, or not allocating stepped care, respectively. Multivariate logistic regression analyses were used to investigate whether GP-related characteristics were associated with depression identification, using a screening instrument, assessment of severity, stepped care treatment, and use of specific interventions, respectively. Dependent variables concerning stepped care allocation and specific interventions were dichotomized (< $50 \%$ and $\geq 50 \%$ of patients). The independent variables age(30 - 40; $41-50 ; 51-$ $64)$ and years of clinical experience with depression care $(1-5 ; 6-15 ; 16-38)$ were categorized into three categories. Whether or not GPs indicated to assess depression severity was used as an additional independent variable in regression models for stepped care treatment and specific interventions, because severity assessment is a possible important factor in choosing treatment intensity. Data was analysed using SPSS version 15.0.

\section{Ethical approval}

The study was carried out according to Dutch privacy legislation. Approval by a medical ethics committee was not required for this study.

\section{RESULTS}

\section{Study population}

A total of 198 GPs (40\%) completed the questionnaire.

Four GPs were excluded because demographic information was missing and/or one or more sections of the questionnaire were filled out poorly. Consequently, 194GPs (39\%) participated in the study. Table 1 outlines their characteristics.

\section{Depression identification and screening}

Descriptive and logistic regression results are depicted in Table 2 and 3, respectively. Over one third of the GPs indicated to pay systematic attention to depression identification in their practice. GPs with special interest in depression and those having structural collaboration with professionals in primary or specialized mental health care were significantly more inclined to do so. One third of the GPs indicated to using a screening instrument, mostly the four-dimensional symptom questionnaire (4DSQ) (18).

' Lack of time ' was by far the most frequently indicated reason for not using a screening instrument. GPs who participated in an improvement project were significantly more inclined to use a screening instrument.

\section{Severity assessment of depression}

Descriptive and logistic regression results are depicted in Table 2 and 3, respectively. Almost two-thirds of the GPs indicated to assess the severity of a newly diagnosed depression in their practice. Unfamiliarity with instruments and insufficient knowledge and skills were the most frequently indicated reasons for not assessing severity. GPs having structural collaboration with professionals in primary or specialized mental health care were more likely to assess severity. Having followed training in depression care was nearly statistically significant associated with severity 
Sinnema, H., Franx, G., Spijker, J., Ruiter, M., Haastrecht, H. van, Verhaak, P., Nuyen, J. Delivering stepped care for depression in general practice: results of a survey amongst general practitioners in the Netherlands. European Journal of General Practice: 2013, 19(4), 221-229

assessment ( $P=0.052$ ). Among the GPs who assessed depression severity, less than one quarter used an instrument, mostly the Beck depression inventory (19). The most frequently reported reasons for not using an instrument were insufficient time and having no instrument available. GPs who participated in an improvement project more frequently used instruments for screening as well as severity assessment, respectively.

\section{[TABLE 1][TABLE 2]}

\section{Stepped care allocation and specific interventions}

Almost three quarters of the GPs indicated to allocate stepped care in their practice to more than half of patients with a newly diagnosed depression (Table 2).

Patients ' preference and having insufficient knowledge and skills were the most frequently indicated reasons to deviate from stepped care. GPs who indicated to determine the severity of depression (as compared to those who did not) and GPs with $6-15$ years of working experience with patients with depression (as compared to those with fewer years of working experience) were significantly more inclined to allocate stepped care treatment(Table 3).

Regarding specific interventions, GPs mostly offered a psycho-education, brief therapy, antidepressants or psychotherapy to patients with newly diagnosed depression(Table 4). Watchful waiting and (online) self-help were less frequently provided. Of note, the frequency with which watchful waiting or antidepressant therapy was offered did not differ between the GPs who indicated to allocate stepped care in most cases and those who did not. GPs with special interest in depression were more inclined to provide psycho-education and male GPs provided brief therapy half as often as female colleagues(Table 5).

\section{DISCUSSION}

\section{Main findings}

This survey among GPs found that about one third of the GPs indicated that systematic identification of depression and using a screening instrument for depression was part of routine work in their practice. Two thirds of GPs indicated to assess the severity of a newly diagnosed depression, generally without using an instrument.

\section{[TABLE 3]}

Almost three quarters of GPs indicated to allocate stepped care to more than half of patients with a newly diagnosed depression. Nevertheless, a minority indicated to start with a watchful waiting approach (29\%) or(online) self-help interventions $(10 \%)$ in more than half of these cases, while four out of ten GPs indicated to start with antidepressants or psychotherapy.

\section{[TABLE 4]}

GPs indicated several barriers to the provision of the studied elements of depression care: insufficient time, knowledge and skills (impede the use of a screening instrument, assessing severity and allocating stepped care); unfamiliarity with screening instruments and lack of reimbursement (impede the use of a screening 
Sinnema, H., Franx, G., Spijker, J., Ruiter, M., Haastrecht, H. van, Verhaak, P., Nuyen, J. Delivering stepped care for depression in general practice: results of a survey amongst general practitioners in the Netherlands. European Journal of General Practice: 2013, 19(4), 221-222

instrument);being not convinced of necessity (impedes the use of instruments for screening and assessing severity); unfamiliarity with tools for severity assessment and the opinion that determination of severity does not affect treatment policy (impede severity assessment); perceived patients ' preference (impedes stepped care allocation). Additionally, several GP-related factors were positively associated with the provision of the studied care elements: having participated in an improvement project regarding depression (with the use of instruments for screening and assessing severity), having a structural collaboration with mental health professionals(with systematic identification of depression and severity assessment), assessing depression severity and having an average number of years of working experience (with stepped care treatment), having special interest in depression (with provision of psycho education)and being female (with provision of brief therapy).

\section{[TABLE 5]}

\section{Study limitations}

First, although a random sample of GPs was approached, the response rate of 39\% may limit the generalizability of the results. This potential limitation is commonly encountered in survey studies among general practitioners (20). Participating GPs were representative for all Dutch GPs regarding age. However, the percentage of women in the study population was somewhat higher than average (43\% versus $38 \%$ ), and respondents may have differed regarding other not measured variables. Given the high percentages observed (see Table 1), it is likely that more respondents had a special interest in depression care, followed training in depression care or participated in an improvement project for depression care compared to the total Dutch GP population. Consequently, it is probable that the results of the present study give a too optimistic view of the provided depression care.

Second, a self-report questionnaire was used with the possible consequence that GPs may have given socially desirable answers and that questions and terminology used could be interpreted in a different way than intended. Another limitation was the cross sectional design of the study. As a consequence, analysis of predictors of allocating stepped care over time was not possible to conduct. Finally, as the survey was confined to GPs actual performance in their general practice, other factors that may influence stepped care provision were not investigated. For example, patient related factors but also access and availability of intervention scan influence the allocation of stepped care(21,22).

\section{Interpretation of findings}

The result that $72 \%$ of the GPs indicated to deliver stepped care in the most newly diagnosed cases of depression, points out that most GPs already apply a stepped care approach. Correspondingly, a recent Dutch trial in general practice did not find an effect of stepped care for depression and anxiety compared with usual care (23). A well-developed usual care was put forward as a possible explanation for this finding. Another possible explanation was the inclusion of a chronic group of patients for whom a stepped care approach may be less suitable (23). Other patient groups may benefit more from stepped care. For instance, a stepped care model in elderly patients with depressive or anxiety symptoms was effective in reducing the risk of onset of depressive and anxiety disorders (24). 
Sinnema, H., Franx, G., Spijker, J., Ruiter, M., Haastrecht, H. van, Verhaak, P., Nuyen, J. Delivering stepped care for depression in general practice: results of a survey amongst general practitioners in the Netherlands. European Journal of General Practice: 2013, 19(4), 221-229

Although most GPs indicated to allocate commonly stepped care, other findings of this study indicate that there still is room for improvement. First, assessing the severity of a newly diagnosed depression was not routinely performed by more than a third of the GPs, whereas severity assessment is an essential element of a stepped care approach. Second, most GPs who mentioned assessing the severity did not use an instrument.

Instruments may be helpful to determine and monitor depression severity, and patients see them as an objective adjunct to medical judgment and as evidence that the GP is taking their mental health seriously (25). Third, $42 \%$ of the GPs indicated that antidepressants were offered to $50 \%$ or more of the patients newly diagnosed with depression, and $45 \%$ of the GPs indicated to do so in combination with psychotherapy.

This finding could be interpreted as indicating that GPs offer antidepressants too frequently as a first step in treatment because of the commonness of sub threshold and mild depression in general practice, the lack of evidence for the effectiveness of antidepressants in mild depression, and the preference of patients with depression for counselling above medication(26,27). Correspondingly, register-based studies have found high antidepressant prescription rates in general practice (4).

Other findings are more difficult to interpret. There latively infrequent use of (online) self-help interventions may be because these interventions were relatively new. Moreover, there is still inadequate evidence that guided self-help is effective in patients with depression in general practice (28).

The finding that only about a third of the GPs indicated to pay systematic attention to depression identification or use a screening instrument may not be surprising given the serious doubts about the effectiveness of standard screening for depression in general practice, even in high-risk populations $(29,30)$. However, from the perspective that a screening instrument can be used to support the communication with patients and the diagnostic process, one may consider 33\% of GPs using a screening instrument a low percentage (7).

\section{Implications for clinical practice and research}

Delivering stepped care for depression in daily general practice could be further improved by stimulating routine assessment of severity of diagnosed depression. Findings indicate that structural collaboration with mental health professionals is associated with the implementation of routine severity assessment. In the Netherlands, structural collaboration between mental health professionals and GPs can be organized in different ways. Future research could be focused on which types of collaboration are (most) effective at facilitating stepped care allocation, including routine severity assessment.

Apart from assessing severity, no modifiable GP related factors were associated with allocating stepped care. This holds true also for specific interventions.

Furthermore, GPs themselves indicated that perceived patients ' preferences and personal lack of knowledge and skills were the most common reasons to deviate from stepped care treatment allocation. Further research among both GPs and patients is needed, to explore the influence of GP-related and patient-related factors on applying stepped care treatment allocation for depression in daily practice. 
Sinnema, H., Franx, G., Spijker, J., Ruiter, M., Haastrecht, H. van, Verhaak, P., Nuyen, J. Delivering stepped care for depression in general practice: results of a survey amongst general practitioners in the Netherlands. European Journal of General Practice: 2013, 19(4), 221-229

\section{CONCLUSION}

This survey indicated that delivering stepped care for depression in daily general practice could be further improved. Collaboration with mental health professionals and routine severity assessment of diagnosed depression is positively associated with allocating stepped care.

\section{ACKNOWLEDGEMENTS}

The authors are grateful to the GPs who participated in the study.

\section{ETHICAL APPROVALT}

he study was carried out according to Dutch privacy legislation. Approval by a medical ethics committee was not required for this study.

FUNDING

Dutch Ministry of Health, Welfare and Sport.

Declaration of interest: The authors report no conflicts of interest. The authors alone are responsible for the content and writing of the paper.

\section{REFERENCES}

1.de Graaf R, Ten Have M , van Gool C, van Dorsselaer S. Prevalence of mental disorders and trends from 1996 to 2009. Results from the Netherlands Mental Health Survey and Incidence Study-2. Soc Psychiatry Psychiatr Epidemiol . $2012 ; 47: 203-13$.

2. Alonso J , Angermeyer M C, Bernert S, Bruffaerts R, Brugha TS,Bryson H, et al . Disability and quality of life impact of mentaldisorders in Europe: Results from the European study of the epidemiologyof mental disorders (ESEMeD) project . Acta Psychiatr Scand Suppl. $2004 ; 420: 38-46$.

3. Gustavsson A , Svensson M , Jacobi F , Allgulander C , Alonso J ,Beghi E , et al . Cost of disorders of the brain in Europe 2010 . Eur Neuropsycho pharmacol 2011; 21: 718- 79.

4. Verhaak PF, van Dijk CE, Nuijen J, Verheij RA, Schellevis FG . Mental health care as delivered by Dutch general practitioners between2004 and 2008 . Scand J Prim Health Care $2012 ; 30: 156-62$.

5. Landelijke Stuurgroep Multidisciplinaire Richtlijnontwikkeling inde GGZ . Multidisciplinary guideline depression: Guideline fordiagnostics and treatment of adult clients with a major depressive disorder [in Dutch] . Utrecht: Trimbos-instituut, 2005.

6. Richtlijnwerkgroep Multidisciplinaire richtlijnen Angststoornissenen Depressie . Multidisciplinary guideline depression: Guideline for diagnostics and treatment of adult clients with a major depressive disorder: First revision [in Dutch] . Utrecht: Trimbosinstituut, 2010 .

7. Van Weel-Baumgarten EM, Van Gelderen MG , Grundmeijer HGLM , Licht-Strunk E, Van Marwijk HWJ, Van Rijswijk HCAM, et al . The NHG guideline depression (second revision of the NHG guideline depressive disorder) [in Dutch] . Huisarts Wet. $2012 ; 55: 252$ -9 .

8. Collaborating Centre for Mental Health. The treatment and management of depression in adults. Clinical guideline 90, partial update of NICE clinical guideline 23. London: National Institute for Health and Clinical Excellence (NICE), 2009.

9. The National Board of Health and Welfare (Social styrelsen).

National guidelines for care in cases of depression and anxiety disorders - summary . Stockholm: The National Board of Health and Welfare, 2004 .

10. New Zealand Guidelines Group. Identification of common mental disorders and management of depression in primary care . Wellington, Ministry of Health , 2008 .

11. Clark DM . Implementing NICE guidelines for the psychological treatment of depression and anxiety disorders: The IAPT experience. Int Rev Psychiatry $2011 ; 23: 318-27$.

12. Rucci P, Piazza A, Menchetti M , Berardi D , Fioritti A, Mimmi S ,et al . Integration between primary care and mental health services in Italy: Determinants of referral and stepped care . Int JFamily Med. $2012 ; 2012: 507464$.

13. Smith MJ , Ackland L , O ' Loughlin S, Young D , Pelosi AJ , MorrisonJ. 'Doing Well' : description of a complex intervention to improve depression care. Primary Health Care Research Development $2010 ; 11: 326$ - 38 . 
Sinnema, H., Franx, G., Spijker, J., Ruiter, M., Haastrecht, H. van, Verhaak, P., Nuyen, J. Delivering stepped care for depression in general practice: results of a survey amongst general practitioners in the Netherlands. European Journal of General Practice: 2013, 19(4), 221-229

14. Lecrubier $Y$. Widespread under recognition and under treatmentof anxiety and mood disorders: Results from 3 European studies . J Clin Psychiatry 2007 ; 68(Suppl 2) : 36 - 41

15. Fernandez A, Haro JM , Martinez-Alonso M , Demyttenaere K ,Brugha TS, Autonell J , et al. Treatment adequacy for anxiety and depressive disorders in six European countries . Br J Psychiatry2007; $190: 172-3$.

16. Smolders M , Laurant M, Verhaak P , Prins M, van Marwijk H ,Penninx B , et al. Which physician and practice characteristics are associated with adherence to evidence-based guidelinesfor depressive and anxiety disorders? Medical Care $2010 ; 48: 2$ 40- 8 .

17. Smolders M, Laurant M, van WA, Grol R, Wensing M. What determines the management of anxiety disorders and its improvement? J Eval Clin Pract. 2008; 14: 25965.

18. Terluin B , van Marwijk HW , Ader HJ , de Vet HC, Penninx BW ,Hermens ML, et al. The four-dimensional symptom questionnaire(4DSQ): A validation study of a multidimensional self-reportquestionnaire to assess distress, depression, anxiety and somatization. BMC Psychiatry $2006 ; 6: 34$.

19. Beck AT, Steer RA, Ball R , Ciervo CA, Kabat M . Use of the Beck anxiety and depression inventories for primary care with medical outpatients . Assessment 1997 ; 3 : $211-9$.

20. Bonevski B , Magin P , Horton G , Foster M , Girgis A . Response rates in GP surveys trialling two recruitment strategies. Aust Fam Physician $2011 ; 40: 427-30$.

21. Prins MA, Verhaak PF , Smolders M , Laurant MG , van der Meer K , Spreeuwenberg P , et al. Patient factors associated with guideline concordant treatment of anxiety and depression in primary care .

J Gen Intern Med. $2010 ; 25: 648-55$.

22. Richards DA, Bower P, Pagel C , Weaver A, Utley M , Cape J , et al .

Delivering stepped care: An analysis of implementation in routine practice . Implement Sci. $2012 ; 7: 3$.

23. Seekles W, van Straten A, Beekman A, van Marwijk H ,Cuijpers P. Stepped care treatment for depression and anxiety in primary care. A randomized controlled trial. Trials $2011 ; 12: 171$

24. van ' $t$ Veer-Tazelaar $P J$, van Marwijk HW, van Oppen $P$, van Hout HP, van der Horst $\mathrm{HE}$, Cuijpers $\mathrm{P}$, et al. Stepped-care prevention of anxiety and depression in late life: $A$ randomized controlledtrial . Arch Gen Psychiatry $2009 ; 66: 297-304$.

25. Dowrick C , Leydon GM , McBride A, Howe A, Burgess H , Clarke P ,et al . Patients ' and doctors ' views on depression severity questionnaires incentivised in UK quality and outcomes framework:Qualitative study . Br Med J. 2009 ; 338 : b663 .

26. Fournier J C, DeRubeis R J, Hollon S D, Dimidjian S , Amsterdam J D, Shelton RC, et al. Antidepressant drug effects and depressionseverity: A patient-level meta-analysis . J Am Med Assoc. $2010 ; 303: 47-53$.

27. Prins MA, Verhaak PF, van der Meer K, Penninx BW, Bensing JM . Primary care patients with anxiety and depression: Need for care from the patient's perspective . J Affect Disord. $2009 ; 119: 163-71$.

28. Coull G , Morris PG. The clinical effectiveness of CBT-based guidedself-help interventions for anxiety and depressive disorders: Asystematic review. Psychol Med. 2011; 41: 2239- 52.

29. Gilbody S, Sheldon T, House A. Screening and case-findinginstruments for depression: A meta-analysis . Can Med Assoc J. 2008 ; 178 : 997 - 1003.

30. $B$ aas K D, Wittkampf K A, v an Weert $H C$, L ucassen $P, H$ uyser $\mathrm{J}$, van den Hoogen $H$, et al. Screening for depression in highrisk groups: prospective cohort study in general practice. Br JPsychiatry $2009 ; 194: 399-403$. 
Sinnema, H., Franx, G., Spijker, J., Ruiter, M., Haastrecht, H. van, Verhaak, P., Nuyen, J. Delivering stepped care for depression in general practice: results of a survey amongst general practitioners in the Netherlands. European Journal of General Practice: 2013, 19(4), 221-222 7

\section{TABLES}

Table 1. Descriptive characteristics of GPs ( $n=194$, unless stated otherwise).

\begin{tabular}{lc}
\hline & $\begin{array}{c}\text { Mean (SD) or } \\
\text { percentage } \\
\text { of GPs }\end{array}$ \\
\hline Demographic characteristics & $46.0(8.7)$ \\
Age, mean age in years (SD) & $43 \%$ \\
Gender (\% female) & $14.9(8.9)$ \\
Clinical experience with depression, mean no. of years (SD) & \\
Interest, training and quality improvement in depression care & $43 \%$ \\
Having special interest in patients with a depression & $68 \%$ \\
Followed a training in depression care in the last three years ( $n=193)$ & $36 \%$ \\
$\quad$ Participated in an improvement project for depression care ( $n=193)$ & $32 \%$ \\
Collaboration & $24 \%$ \\
Structural collaboration with mental health professionals & $12 \%$ \\
Structural collaboration with mental health professionals in primary care & \\
Structural collaboration with professionals in specialized mental health care & \\
\hline
\end{tabular}

Table 2. Performance of GPs ( $n=194$, unless stated otherwise) in their practice regarding depression identification and screening, severity assessment and stepped care treatment.

\begin{tabular}{|c|c|c|c|c|}
\hline \multirow[b]{2}{*}{ Elements of depression care } & \multicolumn{2}{|c|}{$\begin{array}{l}\text { Percentage } \\
\text { of all GPs }\end{array}$} & \multirow[b]{2}{*}{ Reasons for not performing a specific element ${ }^{a}$} & \multirow{2}{*}{$\begin{array}{c}\text { Percentage of } \\
\text { GPs who did not } \\
\text { perform a specific } \\
\text { element }\end{array}$} \\
\hline & Yes & No & & \\
\hline \multicolumn{5}{|l|}{ Identification and screening } \\
\hline Systematic identification of depression & $37 \%$ & $63 \%$ & & \\
\hline \multirow[t]{6}{*}{ Using a screening instrument $(n=192)$} & $33 \%$ & $67 \%$ & Reasons for not using a screening instrument $(n=120)$ & \\
\hline & & & Insufficient time & $63 \%$ \\
\hline & & & Unfamiliarity with screening instruments & $39 \%$ \\
\hline & & & Not necessary for recognition of depression & $33 \%$ \\
\hline & & & No or a lack of reimbursement & $29 \%$ \\
\hline & & & Insufficient knowledge and skills & $26 \%$ \\
\hline \multicolumn{5}{|l|}{ Severity assessment } \\
\hline \multirow{5}{*}{$\begin{array}{l}\text { Severity assessment of newly diagnosed } \\
\text { depression }(n=193)\end{array}$} & $63 \%$ & $37 \%$ & Reasons for not assessing depression severity $(n=66)$ & \\
\hline & & & Unfamiliarity with tools for determining severity & $58 \%$ \\
\hline & & & Insufficient knowledge and skills & $53 \%$ \\
\hline & & & Insufficient time & $27 \%$ \\
\hline & & & $\begin{array}{l}\text { Determination of severity does not affect treatment } \\
\text { policy }\end{array}$ & $21 \%$ \\
\hline \multirow{5}{*}{$\begin{array}{l}\text { Severity assessment and using an } \\
\text { instrument }(n=122)\end{array}$} & $22 \%$ & $78 \%$ & Reasons for not using an instrument $(n=94)$ & \\
\hline & & & Insufficient time & $50 \%$ \\
\hline & & & No instrument available & $48 \%$ \\
\hline & & & The use of an instrument is not necessary & $40 \%$ \\
\hline & & & Insufficient knowledge and skills & $35 \%$ \\
\hline \multicolumn{5}{|l|}{ Stepped care treatment } \\
\hline \multirow{4}{*}{$\begin{array}{l}\text { Allocating stepped care to } \geq 50 \% \text { of } \\
\text { patients newly diagnosed with } \\
\text { depression ( } n=187)\end{array}$} & $72 \%$ & $28 \%$ & $\begin{array}{l}\text { Reasons to sometimes deviate from stepped care } \\
\qquad(n=159)^{\mathrm{b}}\end{array}$ & \\
\hline & & & Perceived patients' preferences & $49 \%$ \\
\hline & & & Insufficient knowledge and skills & $45 \%$ \\
\hline & & & Insufficient time & $33 \%$ \\
\hline
\end{tabular}

${ }^{a}$ Only reasons mentioned by $\geq 20 \%$ of GPs are shown.

bThis question was presented to all 194 GPs, of which $18 \%$ did not fill out a response. 
Sinnema, H., Franx, G., Spijker, J., Ruiter, M., Haastrecht, H. van, Verhaak, P., Nuyen, J. Delivering stepped care for depression in general practice: results of a survey amongst general practitioners in the Netherlands. European Journal of General Practice: 2013, 19(4), 221-222 7

Table 3. Results of multivariate logistic regression analyses to assess associations between GP-related characteristics and GPs' performance in their practice regarding depression identification, depression screening, severity assessment and stepped care treatment allocation.

\begin{tabular}{|c|c|c|c|c|c|}
\hline \multirow[b]{2}{*}{ GP-related characteristics } & \multicolumn{5}{|c|}{ GPs' performance } \\
\hline & $\begin{array}{l}\text { Systematic } \\
\text { identification } \\
\text { of depression } \\
\text { OR }(95 \% \mathrm{CI})^{\mathrm{a}}\end{array}$ & $\begin{array}{c}\text { Using a } \\
\text { screening } \\
\text { instrument } \\
\text { OR }(95 \% \mathrm{Cl})^{\mathrm{a}}\end{array}$ & $\begin{array}{c}\text { Assessing } \\
\text { severity of newly } \\
\text { diagnosed } \\
\text { depression } \\
\text { OR }(95 \% \mathrm{CI})^{\mathrm{a}}\end{array}$ & $\begin{array}{c}\text { Using an } \\
\text { instrument for } \\
\text { severity } \\
\text { assessment } \\
\text { OR }(95 \% \mathrm{Cl})^{\mathrm{a}}\end{array}$ & $\begin{array}{l}\text { Allocating stepped } \\
\text { care treatment to } \\
\geq 50 \% \text { of patients } \\
\text { newly diagnosed } \\
\text { with depression } \\
\text { OR }(95 \% \mathrm{Cl})^{\mathrm{a}}\end{array}$ \\
\hline \multicolumn{6}{|l|}{$\overline{\text { Age }}$} \\
\hline 30-40 years & Reference & Reference & Reference & Reference & Reference \\
\hline $41-50$ years & $0.53(0.21-1.34)$ & $0.62(0.24-1.61)$ & $0.99(0.41-2.40)$ & $0.27(0.04-1.72)$ & $0.98(0.36-2.69)$ \\
\hline $51-64$ years & $0.47(0.16-1.34)$ & $0.70(0.24-2.10)$ & $0.92(0.30-2.80)$ & $0.55(0.14-2.11)$ & $0.44(0.12-1.65)$ \\
\hline Being male & $1.05(0.54-2.05)$ & $1.09(0.54-2.19)$ & $0.65(0.32-1.31)$ & $2.18(0.69-6.83)$ & $0.60(0.28-1.28)$ \\
\hline \multicolumn{6}{|l|}{ Clinical experience } \\
\hline $1-5$ years & Reference & Reference & Reference & Reference & Reference \\
\hline $6-15$ years & $0.74(0.19-2.89)$ & $0.74(0.18-3.08)$ & $2.90(0.72-11.60)$ & $1.99(0.14-28.83)$ & $5.05(1.04-24.53)^{\mathrm{b}}$ \\
\hline $16-38$ years & $0.41(0.15-1.15)$ & $0.59(0.21-1.70)$ & $0.98(0.38-2.55)$ & $0.91(0.08-10.50)$ & $1.93(0.68-5.47)$ \\
\hline $\begin{array}{l}\text { Having structural collaboration with } \\
\text { mental health professionals }\end{array}$ & $2.05(1.01-4.14)^{b}$ & $1.71(0.83-3.50)$ & $2.45(1.12-5.37)^{\mathrm{b}}$ & $2.09(0.79-5.56)$ & $0.82(0.36-1.86)$ \\
\hline Having special interest in depression & $2.35(1.24-4.43)^{c}$ & $1.00(0.51-1.94)$ & $1.88(0.97-3.63)$ & $0.95(0.35-2.61)$ & $1.58(0.76-3.29)$ \\
\hline Followed a training in depression care & $1.70(0.84-3.44)$ & $0.84(0.42-1.69)$ & $1.95(0.99-3.84)$ & $1.32(0.41-4.22)$ & $1.02(0.48-2.16)$ \\
\hline $\begin{array}{l}\text { Participated in an improvement } \\
\text { project for depression care }\end{array}$ & $1.21(0.62-2.38)$ & $3.62(1.86-7.05)^{c}$ & $1.61(0.81-3.21)$ & $3.67(1.34-10.04)^{c}$ & $2.11(0.95-4.70)$ \\
\hline $\begin{array}{l}\text { Assessing severity of newly diagnosed } \\
\text { depression }^{\text {d }}\end{array}$ & - & - & - & - & $2.36(1.13-4.93)^{\mathrm{b}}$ \\
\hline
\end{tabular}

${ }^{\circ} \mathrm{OR}$, odds ratio; $95 \% \mathrm{Cl}, 95 \%$ confidence interval.

b $P \leq 0.05$

${ }^{c} P \leq 0.01$.

dUsed as an additional independent variable in the regression models for stepped care treatment; reference category: GPs who indicated not to assess severity of newly diagnosed depression.

Table 4. Allocated interventions for newly diagnosed depression as indicated by GPs.

Type of intervention, in order of intensity according to the 'stepped care model $^{\text {a }}$
Percentage of GPS providing the intervention to $\geq 50 \%$ of patients newly diagnosed with depression

\begin{tabular}{ll}
\hline Watchful waiting approach $(n=181)$ & $29 \%$ \\
Psycho education $(n=185)$ & $69 \%$ \\
(Online) self-help $(n=176)$ & $10 \%$ \\
Brief therapy $(n=183)$ & $50 \%$ \\
Psychotherapy $(n=182)$ & $40 \%$ \\
Antidepressants $(n=190)$ & $42 \%$ \\
Combination of antidepressants and & $45 \%$ \\
$\quad$ psychotherapy $(n=183)$ & \\
\hline
\end{tabular}

${ }^{a}$ The intervention categories were not mutually exclusive. 
Table 5. Results of multivariate logistic regression analyses to assess associations between GP-related characteriatics and the allocation of interventions by GPs to $\geq 50 \%$ of patients rewly diagnosed with depression

\begin{tabular}{|c|c|c|c|c|c|c|c|}
\hline \multirow[b]{2}{*}{ GP-rel sted characteristics } & \multicolumn{7}{|c|}{ Allocation to $\geq 50 \%$ of patients newly diagnosed with depression } \\
\hline & $\begin{array}{l}\text { Watchful waiting } \\
\text { approach } \\
\text { OR }(95 \% \text { a) }\end{array}$ & $\begin{array}{c}\text { Paycho- } \\
\text { education } \\
\text { OR }(95 \% \text { CI) }\end{array}$ & $\begin{array}{c}\text { (Online) } \\
\text { self help } \\
\text { OR (OS\% CI)" }\end{array}$ & $\begin{array}{c}\text { Brief } \\
\text { the rapy } \\
\text { OR (95\% Cl\% }\end{array}$ & $\begin{array}{l}\text { Psychothe rapy } \\
\text { OR }(95 \%(C))^{\mathrm{a}}\end{array}$ & $\begin{array}{c}\text { Antidepressants } \\
\text { OR }(95 \% \text { a) }\end{array}$ & $\begin{array}{c}\text { Combination of } \\
\text { antidepressare } \\
\text { and } \\
\text { psychothe rapy } \\
\text { OR }(95 \% \text { CI)" }\end{array}$ \\
\hline \multicolumn{8}{|l|}{ Age } \\
\hline $30-40$ years & Reference & Peference & Feference & Refer ence & Reference & Reference & Reference \\
\hline $41-50$ years & $0.59(0.23-1.53)$ & $1.29(0.48-3.42)$ & $0.85(0.22-3.25)$ & $1.51(0.65-3.99)$ & $1.59(0.66-3.85)$ & $1.48(0.52-3.50)$ & $1.31(0.55-3.14)$ \\
\hline $51-64$ years & $1.41(0.45-4.45)$ & $0.52(0.17-1.60)$ & $1.78(0.28-1139)$ & $0.86(0.31-243)$ & $0.87(0.31-2.48)$ & $1.21(0.45-3.31)$ & $0.89(0.32-2.47)$ \\
\hline Being male & $1.05(0.51-2.13)$ & $0.99(0.48-2.06)$ & $0.85(0.30-2.45)$ & $0.47(0.24-0.91)^{b}$ & $0.58(0.30-1.12)$ & $1.20(0.63-2.30)$ & $0.65(0.34-1.25)$ \\
\hline \multicolumn{8}{|l|}{ Clin isal experience } \\
\hline $\begin{array}{l}1-5 \text { years } \\
6-15 \text { years }\end{array}$ & $\begin{array}{c}\text { Reference } \\
0.40(0.00-1 \nabla)\end{array}$ & $\begin{array}{c}\text { Reference } \\
1.98(0.47-8.31)\end{array}$ & $\begin{array}{c}\text { Reference } \\
0.73(0.08-7.05)\end{array}$ & $\begin{array}{c}\text { Reference } \\
2.46(0.63-9.62)\end{array}$ & $\begin{array}{c}\text { Reference } \\
1.01(0.26-3.84)\end{array}$ & $\begin{array}{c}\text { Reference } \\
0.58(0.16-2.14)\end{array}$ & $\begin{array}{c}\text { Reference } \\
1.48(0.39-5.63)\end{array}$ \\
\hline $1 G-3 B$ years & $0.86(0.30-2.44)$ & $1.24(0.45-3.44)$ & $1.69(0.30-9.39)$ & $1.00(0.37-2.65)$ & $0.89(0.34-2.31)$ & $0.62(0.25-1.56)$ & $1.41(0.54-3.67)$ \\
\hline Having structural collaboration with mental hea lth professionals & $1.01(0.43-2.13)$ & $1.65(0.75-3.63)$ & $1.72(0.59-5.05)$ & $1.57(0.83-3.37)$ & $0.84(0.42-1.71)$ & $0.76(0.37-1.53)$ & $0.57(0.33-1.36)$ \\
\hline Hewing special interest in depression & $0.85(0.43-1 \sigma)$ & $2.67(1.31-5.46)^{\mathrm{r}}$ & $1.78(0.62-5.09)$ & $1.70(0.90-3.20)$ & $1.51(0.80-2.85)$ & $112(0.60-2.07)$ & $1.19(0.63-2.24)$ \\
\hline Followed a training in depression are & $0.90(0.44-1.84)$ & $1.38(0.68-2 . \infty 0)$ & $2.27(0.61-8.49)$ & $1.22(0.62-2.42)$ & $1.44(0.72-2.88)$ & $0.69(0.36-1.33)$ & $0.64(0.33-1.24)$ \\
\hline Participated in an improvemert. project for depression care & $1.09(0.55-2.18)$ & $0.82(0.40-1.67)$ & $1.24(0.42-3.69)$ & $0.95(0.49-1.83)$ & $0.6(0.35-1.32)$ & $0.69(0.36-1.31)$ & $0.64(0.33-1.21)$ \\
\hline Assess ing sever ity of newly diagnased depression & $1.16(0.57-2.40)$ & $1.09(0.53-2.22)$ & $0.57(0.22-2.03)$ & $0.58(0.34-1.35)$ & $1.51(0.76-3.01)$ & $1.17(0.50-2.27)$ & $0.59(0.35-1.34)$ \\
\hline
\end{tabular}

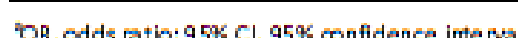

$t p \leq 0.05$.

t $P \leq 0.01$ 